\title{
On the effect of surge protection devices (SPDs) placement for grid-connected solar PV farm
}

\begin{abstract}
The solar PV farm is expected to gain greater popularity in Malaysia as an alternative energy source. Malaysia lies in the tropics and enjoys abundant sunlight, but is also prone to frequent lightning strikes. The solar PV farm is at great risk of being struck by lightning because of its location and installation in an open and flat area. Due to the high cost of maintaining the solar PV farm, a suitable lightning protection system should be installed to avoid or minimise the potential damage. Hence, the objective of this study is to offer a basic reference for the installation of a surge protection device (SPD) for a proper location according to the standard.
\end{abstract}

Keyword: Solar PV farm; Lightning current waveshape; Transient voltage; Transient current; SPD; Cable length 